\title{
Reflections on Paratextual Markers and Graphic Devices in Ur III Administrative Documents
}

\author{
Christina Touparopoulou ${ }^{1}$
}

\begin{abstract}
Mining 15,000 cuneiform inscribed clay documents, albeit with about 10 lines of text each, this article discusses elements appearing on these tablets beyond text which accentuated in a visual way the structure of the documents and usually aided or, in some instances, obscured their reading and subsequent interpretation. These paratextual markers and graphic devices are left-edge inscriptions, rulings, blank spaces, and sealings that added information not available from the text alone.
\end{abstract}

$\mathrm{D}$

URing the Ur III period in AnCient Mesopotamia (2II22004 BCE; middle chronology), one of the most centralized bureaucratic systems ever known was being practiced. Every daily transaction related to the government's functioning was documented by the king's officials and carried forward into monthly and annual summaries. We now have a corpus of more than 120,000 clay tablets, documenting minute details of the system, all brought to light since the end of the nineteenth century. This abundant textual material provides us with one of the most comprehensive sets of textual data for the day-to-day administrative procedures of any ancient bureaucracy. On tiny tablets (usually about $3 \times 3 \mathrm{~cm}$ ) scribes

1. For the writing of this paper, the author acknowledges support by the Heidelberg Collaborative Research Centre 933 'Material Text Cultures. Materiality and Presence of Writing in Non-Typographic Societies', (Subproject No. C01UP2 The Materiality and Presence of Writing in the Ancient Mesopotamian Discourse of Power between 2500 and 1800 вC - Archaeology), funded by the German Research Foundation (DFG). I would like to thank A. Karagianni for constructive discussions, N. Oldsen for help with formatting the text and bibliography and M. Richardson for correcting the English of the manuscript.

Textual Cultures 8.2 (2013): 1-14. DOI: 10.14434/tc.v8i2.13276. 
documented what commodities were transported and what they were used for, who were the people responsible for almost all the transactions (including the identity of family members and their status in the hierarchy), as well as the way these individuals functioned within the administration and the bureaucratic procedures they followed. Moreover, the different styles and shapes of the tablets have specific relevance for the reconstruction of administrative practices.

A clearer picture of bureaucratic norms in the Ur III period is better acquired by combining textual, iconographical, and archaeological data than by looking at each of these aspects alone. By iconographical I mean here the aesthetics of text and the surface of the text, the structure and format of the text, and the text-medium. That medium is a clay document, whether a tablet, an envelope encasing the tablet, or perforated and differently shaped (polyhedral, ovoid, oblong, triangular, spherical) clay objects called 'bullae' which were used as labels and tied to some kind of container. The bulk of the evidence is so exhaustive that it does not easily lend itself to a study of the material aspects of those documents. Even so, the aim of this article is to highlight markers that established and shaped (or were shaped by) the administrative norms, several paratextual notations and graphic devices that visually accentuated the structure of the document and obscured or aided its reading and subsequent interpretation.

\section{Paratexts}

Although writing and text are usually intertwined, one should also acknowledge that text can be seen as "any configuration of signs that is coherently interpretable by some community of users" (Hanks 1989, 95). In this manner, contingent forms of text such as meta-text, pre-text, subtext and con-text, should also be taken into consideration when looking at the qualities and material aspects of texts. According to Gérard Genette paratexts are:

Those things in a published work that accompany the text, things such as the author's name, the title, preface or introduction, or illustrations. More than a boundary or a sealed border, the paratext is, rather, a threshold ... a zone between text and off-text, a zone not only of transition but also of transaction: a privileged place of pragmatics and a strategy, of an influence on the public, an influence that ... is at the service of a better reception for the text and a more pertinent reading of it $(1997,1-2)$. 
Any ancillary material impressed, inscribed, added to the text acts as a mediator of interpretation and even though considered marginal, in reality these markers/notations control one's reading of the main text. ${ }^{2}$ As such, they might also obscure the reading of the text, as we will discuss below, or they could add important information missing from the main text.

Such notations and paratextual features can be the marginalia in medievalists' parlance, or the scholia in Classicists' nomenclature, both of which seem equivalent to the colophons of the Mesopotamian scribal culture. Colophons appear from time to time in the Old Babylonian mathematical and school tablets (early second millennium $\mathrm{BCE}$ ) and become more prominent in first millennium texts. Christine Proust studies the mechanisms of colophons/paratexts in Old Babylonian mathematical and school tablets with the aim of highlighting the processes for the creation and classification of mathematical knowledge (Proust 2012). Niek Veldhuis similarly studied the colophons and editorial remarks on first millennium tablets (Veldhuis 1999). In the colophon of copied texts the name of the scribe, the provenance of the original and other editorial comments were documented in an effort to adhere most closely to the content and structure of the original document (Veldhuis 1999, 170). However, colophons in first millennium texts acted more as meta-text, adding information on the production of the text and included on the tablet after the main text was finished (Hunger 1968, especially nos. 317-39; Leichty 1964) akin to the colophons in medieval studies.

While modern editors' remarks when editing cuneiform documents as paratexts or meta-texts (such as the transliterations, transcriptions, translations and even .xml markup language of the cuneiform tablets) is open for discussion, here I intend to discuss only those paratextual characteristics that were written contemporaneously with the original text, those elements that aimed at a better (or nuanced) reception of the message of the tablet by the scribes themselves. I argue that a variety of other markings observed on Ur III administrative texts constitute paratexts, such as the left-edge inscriptions and the documentation of the date, but of most relevance are the sealings that appear on numerous documents of an administrative nature. Rulings and blank spaces are treated as graphic devices that aided in the reading of the text and unintentionally identified the author of the text.

2. See also Kraft 2007 for "para-biblical" notations. 


\section{Ur III Administration and its Documentation}

Ur-Namma, a general of Ur in Southern Mesopotamia, established a dynasty dominating a territory stretching east into Iran and north towards the borders of Northeastern Syria, Northern Iraq and Northwestern Iran. This "empire" was consolidated when his son Shulgi succeeded to the throne. Shulgi and his successors (Amar-Sin, Shu-Sin and Ibbi-Sin) managed to create a unified administration for Sumer and Akkad, which was the heart of the Ur III Empire. It was divided into some 23 provinces or city-states, each ruled by a civil governor, selected from the local aristocracy (HALlo 1953; DAHL 2007). The rest of the empire comprised around 90 settlements, each of which was under the control of a military officer (Sallaberger 1999). The authorities of the Ur III period struggled for centralization, which resulted in standardization in economic and administrative practices, and also in the art of the period. Centralization however was not accomplished as completely as was once thought on all levels of society, since the Ur III Dynasty included urban centers whose inhabitants carried on their own traditional procedures and who continued functioning and living in accordance with their local customs. Therefore, the Ur III state and bureaucracy was "constrained" to run along patrimonial lines and to keep already highly established members of local households in key positions (GARfinkle 2008). Nonetheless, on a national level the state administration required a minute documentation of its government's functioning.

The need for such excessive and dense documentation is more evident in the corpus produced by an administrative center specifically created to serve the purposes and needs of this new bureaucracy, and to control the livestock management of the state. Drehem (ancient Puzrish-Dagan) was a newly founded establishment, where all officials were chosen by the king, and which was administered only for the state's well being. The tell of Drehem, located today in southern Iraq, was never systematically excavated until 2007. Looting began in 1909-1910, common in the land between the two rivers at the time, and since then thousands of tablets have come to light and are now to be found in museums and collections around the world.

The total number of documents attributed to Drehem is still growing (more than 15,000 in 2013 according to the Cuneiform Digital Library Initiative or CDLI). These documents are purely administrative, recording the running of the livestock agency, the receipts of animals, their distribution for cultic, diplomatic, and other purposes, the documentation of 
newborn animals, the processing of animals that died accidentally or those that should be slaughtered; they also provide a glimpse into the administrative structure and the functionaries of an Ur III state agency. Most of the documents have a common structure and format, enabling one to understand their content based on appearance alone. Among these common characteristics are the inscriptions running on the left edge of the tablets (called the left-edge inscriptions), the rulings and the spaces left between the different transactions or parts of transactions documented on the tablets, as well as the seal impressions. Such markers do not appear at random but are usually consistent within the Drehem corpus. I will treat these notations as paratexts and graphic devices, to be seen as different in form and function from the colophons on documents from later periods of the Mesopotamian scribal culture. These features, the left-edge inscriptions, the sealings and the rulings, add information "on top of" the text, where "on top of" has both literal and metaphorical significance, since seals were sometimes rolled on top of the clay onto which the text had been written.

\section{Left-edge Inscriptions as Paratexts}

Many cuneiform tablets from Drehem had text written along the left edge. This left-edge inscription was possibly introduced as an aid for archiving and subsequent checking of the tablets. ${ }^{3}$ It is possible that tablets with an inscription on the left edge were shelved, so the function of that inscription would be like that of the lettering on a spine of a modern book. It is easy to understand how that left-edge inscription would help when filing tablets, as it would be visible to anyone consulting a store of tablets. And anyone could calculate quickly how many animals had been dealt with in a specific bureau, if the total number of animals in a document was given on the edge. However, the content of this inscription was not always uniform within the administrative apparatus of the Ur III livestock agency at Drehem. During the first years of the bureaucracy, the scribes at Drehem could have noted the precise day of the month the transaction took place (fig. 1a). But later, scribes belonging to specific bureaus within the state administration started adding to the left edge the total number of animals

3. Here only some features of the inscriptions appearing on the left edges of tablets from Drehem will be presented; a fuller discussion on left-edge inscriptions is to be found in the forthcoming book by the author provisionally entitled An Entangled State Administration in Late Third Millennium вс Mesopotamia: Governing (through) Clay, Leather, Bitumen, Stone, Reed. 


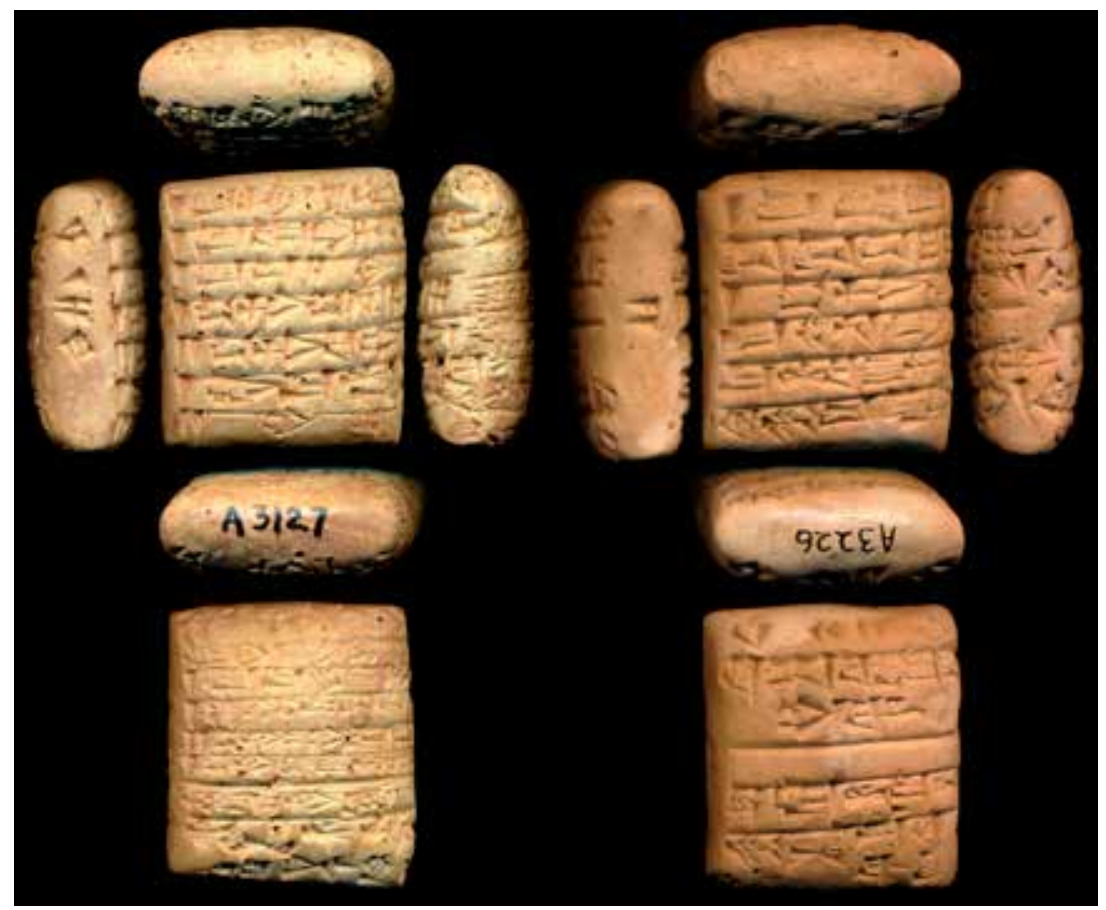

Figure 1. Two examples of clay tablets with a left-edge inscription. The tablet on the left (A 3127) documents on its left edge the date the transaction took place. Dimensions: $35.5 \times 31 \times 15.5 \mathrm{~mm}$ (C) Oriental Institute, University of Chicago. The tablet on the right (A 3226) documents on its left edge the total number of animals handled in this transaction. Dimensions: $37 \times 32 \times 16 \mathrm{~mm}$ (C) Oriental Institute, University of Chicago

dealt with within the text (fig. 1b). So there was no norm for the content of the left-edge inscription, but each bureau chose its own style. By switching from recording a specific day for the transaction to the total number of animals would definitely help for referencing, and for finding corresponding texts documenting the expenditure of animals delivered to the charge of other officials, especially for the official charged to check these accounts at the end of the accounting period. The left-edge inscription was not simply a formulaic innovation but rather a characteristic of certain bureaus that was eventually imitated by others.

Interestingly, it is only documents of unilateral nature, those that document transactions within the internal administration of the agency, that 
had a left-edge inscription; almost all bilateral records, documents produced to record a transaction between two parties, one of whom was usually independent from the livestock agency, did not have a left-edge inscription. Such paratextual information seems to have been a conscious addition on behalf of the state scribes/officials, differentiating between documents of a unilateral and a bilateral nature. ${ }^{4}$

\section{Rulings and Blank Space as Graphic Devices}

All unsealed administrative Drehem tablets, those that did not bear the impression of a cylinder seal on their surface (to be discussed in more detail below), were ruled. Various types of ruling exist; some tablets had fine, straight lines while others were more roughly drawn. This is evidence of different scribal hands, which can be individually identified. Most rulings were probably made with a stylus, but some could have been made with a string (TAYLOR 2011, 15). On some tablets there are double rulings.

Sealed Ur III tablets were generally not ruled (see also SuchGuttiérez 2008). But in the Drehem corpus 24 per cent of the sealed corpus were ruled. While in the Nippur corpus all ruled and sealed tablets were of legal nature, usually sale documents (Hattori 2001), Drehem sealed and ruled tablets are not restricted to a specific type of transaction. From the extant corpus of Drehem sealed documents information about ruling comes from 1577 documents, either from photographs or from drawings. Of those sealed and ruled tablets (fig. $2 \mathrm{~b}$ ), 21 per cent were mostly sealed by the same officials (i.e. Adda-kala, Nur-Suen, Nur-Adad, Nannamaba, etc.), while the unruled and sealed ones (fig. 2a) were mostly sealed by Ur-Shulpae, Ur-ku-nuna, Ur-mes and a few others.

Distinguishing ruled from unruled tablets may provide an insight into who wrote the tablet. One's first impression is that the person who wrote the tablet was the person who sent out the animals/products, that is the originating official. But there is no correlation between whether a tablet was ruled or not and the content of that tablet, the products documented on it, the official acting in the disbursement or any particular bureau/office or administrative unit. Rulings or the lack of them had nothing to do with the internal organization and administrative practices but they seem to have been closely related to the person who sealed the tablet. Moreover, whether or not to rule a tablet was left to the actual author of the tablet to

4. For unilateral and bilateral documentation, see now Postgate 2014. 


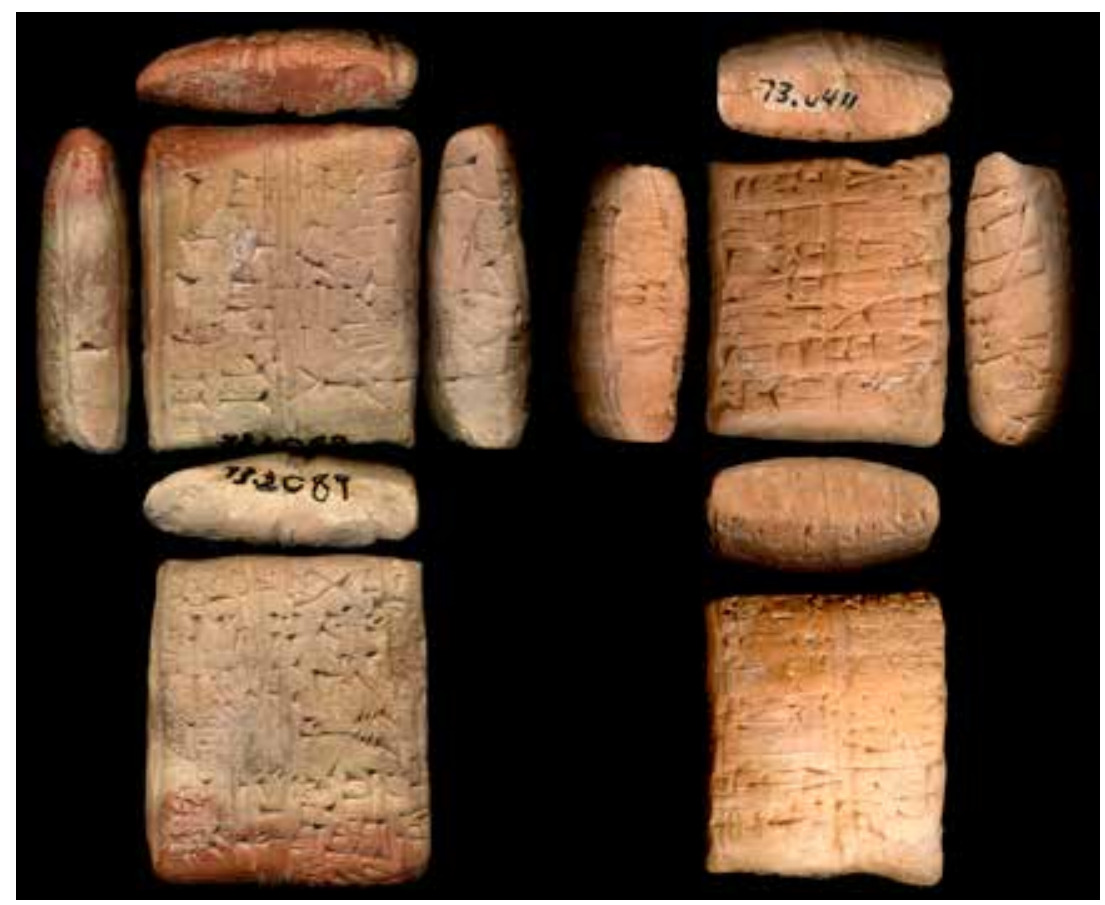

Figure 2. On the left, a sealed and unruled clay tablet from Drehem, Ur III period; the sealer is Ur-Shulpae. Dimensions: $47 \times 40$ mm; AUAM 73.2089, photo courtesy of Cuneiform Digital Library Initiative (C) Andrews University, Horn Archaeological Museum. On the right, a sealed and ruled clay tablet from Drehem, Ur III period; the sealer is Nur-Adad. Dimensions: $43 \times 35 \mathrm{~mm}$; AUAM 73.0411, photo courtesy of Cuneiform Digital Library Initiative (C) Andrews University, Horn Archaeological Museum.

choose, whatever was the nature of the transaction and whoever were the participating officials. It would be counterintuitive for a scribe to write a tablet intended to be sealed by official $x$ with rulings and another intended to be sealed by official $y$ without.

With these rulings the scribes separated the various sections of the text, either by leaving blank space, or using double lines. The space left blank often separated the various sections of the text, such as the date, usually the year-name, or the main transaction when the text was long (fig. 3). It is interesting here to note that the actual day was not specified in the place reserved for the date, but it was incorporated into the main body of the text, so that the para-information was the year rather than the day and the 


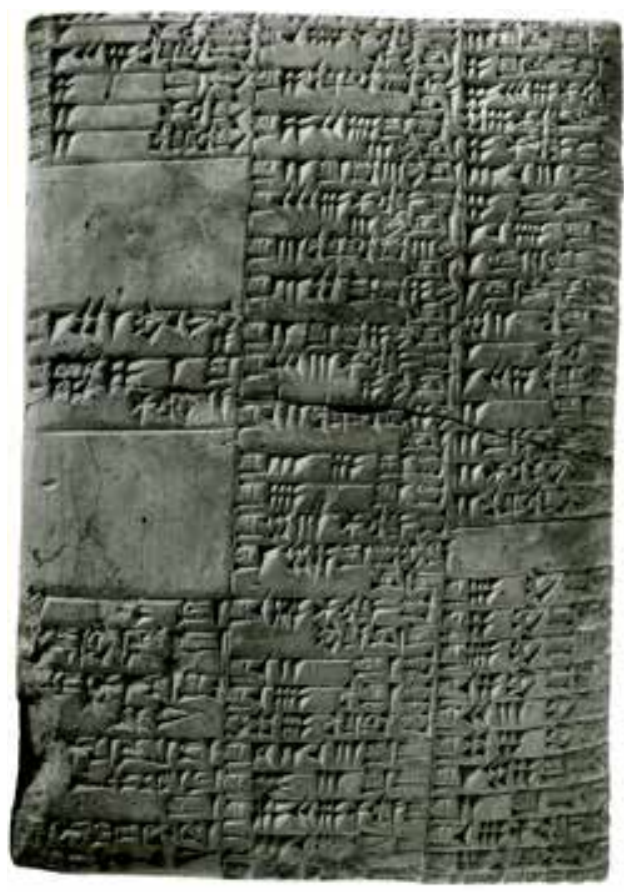

Figure 3. A ruled and unsealed clay tablet with three columns of text on each side; Dimensions: $95 \times 139 \mathrm{~mm}$. It enlists herds of oxen, sheep, ewes, lambs and goats in charge of a herdsman; Ur III period, around 2029 все, Drehem. Here the reverse side is shown, with rulings and blank space left to separate the different entries of the text (date, final transaction). BM 103406 (C) Trustees of the British Museum

month. However, this seems to contrast with the specification of the day on the left-edge inscriptions from early on when the Drehem livestock agency was functioning.

Rulings and blank space on administrative tablets as discussed here seem to act as a frame into which text was incorporated. This frame acted more as a paratextual marker, accentuating the individual habits of the scribes and enabling them to be identified. Its function was different from the left-edge inscription, in that it offered no extra information on the content of the text but rather on its author and this is why these markers conform best to graphic devices. ${ }^{5}$

5. For interesting discussions on graphic devices in ancient texts see articles in Korpel and Oesch 2005 and Korpel, Oesch and Porter 2007. For 'visual 


\section{Sealings as Paratexts}

Seals were stamped on clay surfaces in Mesopotamia from at least the 7th millennium $\mathrm{BCE}$. However, it was only in late 4th millennium $\mathrm{BCE}$, during the Uruk period, that they appeared together with writing. They were impressed on clay tablets bearing numerical notations and cuneiform signs, on the so-called archaic tablets. From the end of the 4th millennium until the end of the 3rd millennium the practice of sealing cuneiform documents was scarce, whereas the sealing of other media, such as baskets, doors, pots and tags, was common. Whether this was an intentional difference or due to fortuitous discoveries is hard to say. What can be said, since sealed documents from the Ur III period can be counted in thousands, is that only during this period did rolling a seal on a document become the mainstream practice. Almost 20\% of the documents produced in state and provincial administrations during the Ur III period were sealed. The percentage for the Drehem corpus is a little less, with around 2,800 documents out of a total of more than 15,000 being sealed. Nevertheless, the Drehem corpus provides a unique opportunity to study the sealing practice and the relation of the seal to the text written on the document.

The way a seal impression was presented was more or less uniform among officials. It could be repeated in various positions on the tablet, but not randomly applied. It was rolled vertically, against the horizontal lines of text, usually after the writing of the text had been finished. It covered the whole available writing surface, with the legend of the seal oriented in line with the text and impressed several times, according to the size of the tablet (see fig. 2). The main aim was to show the legend of the seal rather than the scene. If the scene was also obvious that was incidental, not deliberate. Some sealing techniques can be seen to be characteristic of particular officials when examined in detail.

Both ruled and unruled tablets have the same vertical column formats for the cylinder seal. It was rolled up and down the obverse and the reverse of the tablet. Sometimes three edges of the tablet were sealed, but never the bottom edge because that was the edge on which the tablet rested when archived on shelves and/or in baskets. It was rolled along the left edge of a tablet, the visible edge after archiving, in such a way that its legend flow in the same direction as the text of the tablet. It has been suggested that a space was left on a tablet, designated as the position where the seal was to

and spatial devices used to convey categorical and nominal relations', see TVERsку 2001, esp. 91-96, and table 4.1. 
be applied (Postgate 1986, 11-2; Postgate 2014, 76). ${ }^{6}$ While officials naturally preferred to roll their seal on any space left on the reverse after the writing of the text was completed, to make it more legible, that blank space on the Ur III tablets had certainly not been designated for a seal impression.

A tablet was sealed at the same time that it was written, and in most cases sealed and written by the same person. Some tablets were sealed before they were written, with the seal acting as a kind of letterhead identifying the scribe (Reichel 2003) and creating again a frame upon and within which the text was to be incorporated. Although few sealers preferred to rule their tablets, generally sealed tablets were left unruled.

Postgate has noted that the introduction of the sealing practice in tablets documenting the internal business of Puzrish-Dagan can signify a shift from a unilateral to a bilateral mode of documentation and thus organization (Postgate 2001, 187). But that cannot be. His explanation that this shift was attributable to the increasing distance between the concerned parties does not seem to be in accordance with the current evidence from the sealed tablets. It was mostly during the reigns of Shulgi and Amar-Sin that the sealing occurred on tablets documenting dealings between Puzrish-Dagan officials and people outside the Puzrish-Dagan internal organization - what Postgate calls bilateral documentation - , when the sealing of tablets was least frequent. During the reign of Shu-Sin, when sealing was ubiquitous, most of the sealed tablets documented transactions related to the internal organization of Puzrish-Dagan and were sealed by officials who seemed closely related to the officials responsible for the transactions, possibly the latter acting as the scribes of the former - what Postgate calls unilateral documentation.

\section{Conclusion}

These paratexts and graphic devices on the Ur III administrative documents cannot be equated to colophons, marginalia or scholia. They were not comments made by copyists, as most of the marginalia or the colophons were, but text and other markers added next and in close association to the text to accompany it and add information most usually on the author of the

6. See also https://www.smm.org/anthropology/cuneiform/sealing (last accessed 25.04.2014), where the author of this short commentary on sealing practices writes that the seal was rolled on the blank space of the tablet reserved for it. 
administrative document, either for him/her to accept liability or to just imprint his/her identity often possibly unintentionally.

The content of a sealed tablet can reveal hints about ancient methods of administrative organization. The text of the tablet cannot and should not be studied individually. It is not only the written text that reveals patterns for the history of administration in the period under investigation, but also the way the tablet was written and the way the seal was impressed on it that can give us clues as to its function within the sphere of administration. Paratextual markers and graphic devices, such as left-edge inscriptions, space deliberately left to divide the text, rulings and sealings, all accentuated and added information otherwise unavailable from the text itself. It is only through a holistic approach, a functional and contextual approach to the vast administrative documentary material, that we can start unraveling the hints and minutiae of bureaucratic and administrative norms. And with this approach we can start seeing the agent behind these bureaucratic devices, the scribes who in such minute ways negotiated their presence and transmitted knowledge.

University of Heidelberg

\section{Works Cited}

DAHL, Jacob L. 2007. The Ruling Family of Ur III Umma: A Prosopographical Analysis of a Provincial Elite Family in Southern Iraq ca. 2100-2000 BC. Leiden: PIHANS 108.

Garfinkle, Steven J. 2008. "Was the Ur III State bureaucratic? Patrimonialism and Bureaucracy in the Ur III period". In The growth of an Early State in Mesopotamia: Studies in Ur III administration (Proceedings of the First and Second Ur III Workshops at the 49th and 51st Rencontre assyriologique internationale, London July 10, 2003 and Chicago July 19, 2005), edited by Steven J. Garfink Le and Justin Cale Johnson, 55-61. Madrid: Consejo Superior de Investigaciones Científicas.

Genette, Gérard 1997, Paratexts: Thresholds of Interpretation. Trans. Jane E. Lewin. Cambridge: Cambridge University Press.

Hallo, William W. 1953. The ensi's of the Ur III Dynasty. PhD thesis, Chicago Oriental Institute.

Hanks, William F. 1989, "Text and Textuality”. Annual Review of Anthropology 18: 95-127. http://dx.doi.org/10.1146/annurev.an.18.100189.000523.

7. Paratexts similar to the illustrations appearing in the margins of medieval manuscripts are treated in another forthcoming article from the author, and one can also see WANGESONner 2009 for a discussion of such doodles and drawings on Mesopotamian clay tablets. 
Hattori, Atsuko 2001. "Sealing Practices of Ur III Nippur". In Seals and Seal Impressions, Proceedings of the XLV Rencontre Assyriologique Internationale, edited by William W. Hallo and I. J. Winter, 71-99. Bethesda, MD: CDL Press.

Hunger, Hermann 1968. Babylonische und assyrische Kolophone. Neukirchen-Vluyn: Verlag Butzon \& Berker Kevalaer.

Korpel, Marjo C.A. and Josef M. Oеsch (eds.) 2005. Layout Markers in Biblical Manuscripts and Ugaritic Tablets. Pericope 5 - Scripture as written and read in antiquity. Leiden: Brill.

Korpel, Marjo C.A., Joseph M. Oesch and Stanley E. Porter (eds.) 2007. Method in Unit Delimitation. Pericope 6 - Scripture as written and read in antiquity. Leiden: Brill.

Kraft, Robert 2007. "Para-mania: Beside, Before and Beyond Bible Studies". Journal of Biblical Literature 126: 3-27.

Leichty, Erle 1964. "The Colophon”. In Studies Presented to A. Leo Oppenheim, edited by Robert D. Biggs and J. A. Brinkman, 147-55. Chicago: Oriental Institute.

Postgate, John Nicholas 1986. "Middle Assyrian tablets: the instruments of bureaucracy". Altorientalische Forschungen 13: 10-39. http://dx.doi.org/10.1524/aofo.1986.13 .12 .10 .

- "System and style in three Near Eastern bureaucracies". In Economy and Politics in the Mycenaean Palace States. Proceedings of a Conference held on 1-3 July 1999 in the Faculty of Classics, Cambridge, edited by Sofia Voutsa KI and John Killen, 181-94. Cambridge: Cambridge Philological Society 27.

- 2014. Bronze Age Bureaucracy. Writing and the Practice of Government in Assyria. Cambridge: Cambridge University Press.

Proust, Christine 2012. "Reading Colophons from Mesopotamian Clay-Tablets Dealing with Mathematics". NTM Zeitschrift für Geschichte der Wissenschaften, Technik und Medizin 20/3, 123-56. http://dx.doi.org/10.1007/s00048-012-0071-z.

Reichel, Clemens 2003. "Appendix: Sealing practice”. In: Markus Hilgert, Drehem Administrative Documents from the Reign of Amar-Suena (Oriental Institute Publications 121), 603-24. Chicago: The Oriental Institute.

Salla Berger, Walther 1999. "Ur III-Zeit". Mesopotamien: Akkade-Zeit und Ur III-Zeit, Orbis Biblicus et Orientalis 160/3, 121-392. Freiburg: Universitätsverlag.

Such-Gutiérrez, Marcos 2008. "Gesiegelte Urkunden der königlichen Viehverwaltung von Drehem und die Frage der Linienunterteilung und Siegelung dieser Tafeln". In On the Third Dynasty of Ur: Studies in honor of Marcel Sigrist, edited by Piotr Mich alowski, 201-16. Boston: American Schools of Oriental Research.

TAYLOR, Jonathan 2011 "Tablets as artefacts, scribes as artisans". In Oxford Handbook of Cuneiform Culture, edited by Karen Radner and Eleanor Robson, 5-31. Oxford: Oxford University Press.

Tversky, Barbara 2001. "Spatial Schemas in Depictions". In Spatial Schemas and Abstract Thought, edited by Merideth Gattis, 79-112. Cambridge MA: MIT Press. Veldhuis, Niek 1999. "Reading the Signs". In All Those Nations ... ., Cultural Encounters within and with the Near East: Studies Presented to Hans Drijvers at the 
Occasion of His Sixty-fifth Birthday by Colleagues and Students, edited by Herman L. J. Vanstiphout, with the assistance of Wout J. van Beккum, Geert Jan H. van Gelder and Gerrit Jan Reinink, 161-74. Groningen: Styx Publications.

WAGENSONNER, Klaus 2009. "Non-textual markers or pseudo-written references. Some glimpses from the Mesopotamian field". In Non-Textual Marking Systems, Writing and Pseudo Script from Prehistory to Modern Times, edited by Petra Andrássy, Julia Budka and Frank Kammerzell, 33-67. Göttingen: Seminar für Ägyptologie und Koptologie. 